\section{International Scientific Journal Theoretical \& Applied Science}

Ekaterina Andreevna Zaitseva

student,

Financial University under the Government of the Russian Federation (Kaluga Branch),

Russia

zaytsewa.katyuschka@yandex.ru

Year: $2015 \quad$ Issue: $07 \quad$ Volume: 27

Published: $30.07 .2015 \quad$ http://T-Science.org

SECTION 31. Economic research, finance, innovation, risk management.

\title{
EDUCATION IN THE KALUGA REGION: CHARACTERISTIC, QUESTIONS OF FINANCING AND ANALYSIS OF THE MAIN INDICATORS
}

\begin{abstract}
The basics of education Kaluga region in the context of pre-primary, primary, secondary and higher education are presented in this article, control methods gained studying knowledge at elementary, main and high school are considered. The analysis of the number of educational institutions in the region and the number of students and also expenses of the regional budget of the Kaluga region on education for articles is carried out, the corresponding conclusions are drawn.

Key words: education, Kaluga region, pre-primary education, primary education, basic general education, the basic state exam, secondary education, Unified State Exam, secondary and higher vocational education, the costs of the regional budget.

Language: Russian

Citation: Zaitseva EA (2015) EDUCATION IN THE KALUGA REGION: CHARACTERISTIC, QUESTIONS OF FINANCING AND ANALYSIS OF THE MAIN INDICATORS. ISJ Theoretical \& Applied Science 07 (27): 183-191.

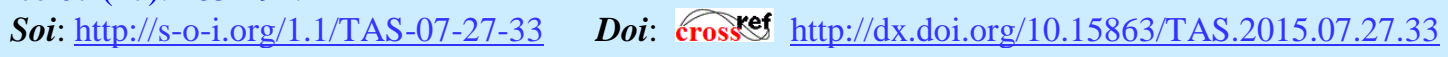

\section{ОБРАЗОВАНИЕ В КАЛУЖСКОЙ ОБЛАСТИ: ХАРАКТЕРИСТИКА, ВОПРОСЫ ФИНАНСИРОВАНИЯ И АНАЛИЗ ОСНОВНЫХ ПОКАЗАТЕЛЕЙ}

Аннотация: В статье представлена организация образовательной деятельности в Калужской области в разрезе дошкольного, начального, основного, среднего и выстего образования, рассмотрены методы контроля получаемых учашимися знаний в начальной, основной и старшей школе. Проведен анализ количества образовательных учреждений региона и численности учащихся, а также расходов областного бюджета Калужской области на образование по статьям, сделаны соответствующие выводы.

Ключевые слова: образование, Калужская область, дошкольное образование, начальное образование, основное общее образование, ОГЭ, среднее общее образование, ЕГЭ, среднее и высшее профессиональное образование, расходы областного бюджета.
\end{abstract}

Социально-экономический потенциал развития общества во многом зависит от состояния системы образования. Уровень и качество образования определяют также развитие и функционирование общества в целом и каждого человека в отдельности. Именно поэтому все государства уделяют огромное внимание данному направлению социальной сферы, выделяя на его финансирование большие объемы денежных средств. Более того, правильно структурированная система образования в значительной степени предопределяет устойчивое развитие государства.

Кроме того, как известно, образование - это

ISPC Intelligent technologies, процесс усвоения знаний. В ходе эволюции человеческой цивилизации область знаний, истории становится все шире. Следовательно, для дальнейшего развития общества каждый индивид не только должен способствовать движению вперед, но и иметь ввиду уже накопленные предками понятия и факты для объективного понимания и анализа сложившихся в мире ситуаций. Поэтому повышение уровня и качества образования в обществе является одной из основных функций каждого государства.

Так, несмотря на снижение количества учебных заведений в Российской Федерации и численности в них обучающихся, объем
Marseille, France

ches, 
финансового обеспечения образования не только не сокращается, а даже увеличивается, что должно послужить всестороннему развитию российского государства и увеличению уровня и качества жизни россиян [6, с.275].

Действительно, качество образования населения любого государства, в том числе и российского, определяет его экономическое, социальное и правовое развитие, а также оказывает непосредственное влияние на уровень жизни россиян [8, с.75].

Согласно Федеральному закону «Об образовании в Российской Федерации» «образование - это единый целенаправленный процесс воспитания и обучения, являющийся общественно значимым благом и осуществляемый в интересах человека, семьи, общества и государства, а также совокупность приобретаемых знаний, умений, навыков, ценностных установок, опыта деятельности и компетенции определенных объема и сложности в целях интеллектуального, духовнонравственного, творческого, физического и (или) профессионального развития человека, удовлетворения его образовательных потребностей и интересов» [2].

В Конституции Российской Федерации указано, что каждый имеет право на получение бесплатного дошкольного, основного общего и среднего профессионального образования, а также на получение бесплатного высшего профессионального образования на конкурсной основе. Кроме того, основное общее образование в России является обязательным для всех граждан [1, п. 1-4, ст. 43, гл. 2].

Необходимо отметить, что образовательная система Российской Федерации имеет специфические черты, не характерные для систем образования других государств. Но, тем не менее, Россия стремится приблизиться к европейским стандартам образования. В частности, об этом свидетельствует присоединение Российской Федерации в 2003 году к Болонскому процессу, целью которого является создание единого европейского пространства высшего образования.

Согласно п. 4 и 5 ст. 10 вышеуказанного закона в Российской Федерации устанавливаются уровни образования, представленные на рисунке 1 .

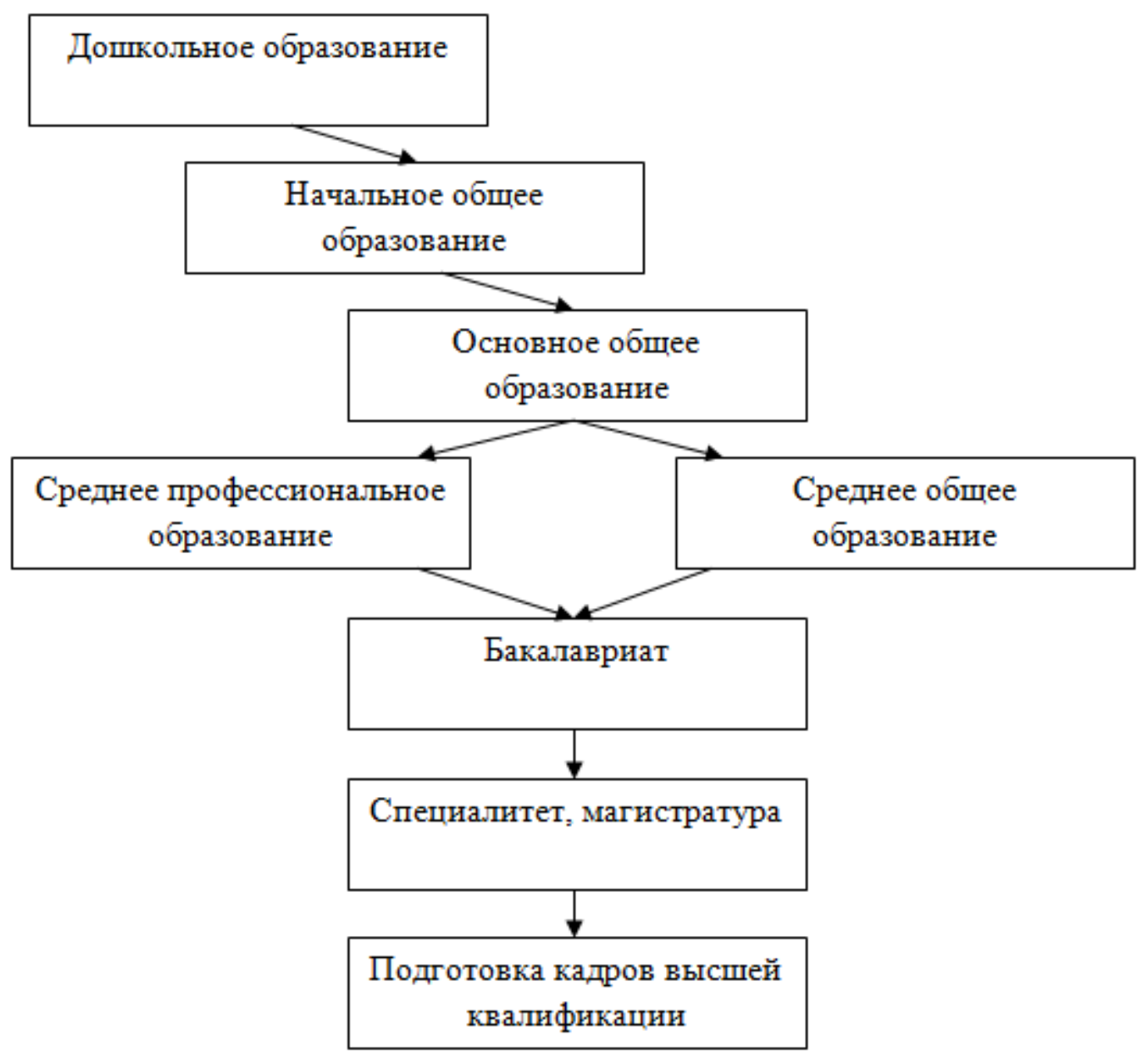

Рисунок 1 - Уровни образования в Российской Федерации. 
В рамках данной статьи вышеуказанные уровни образования будут рассмотрены на примере Калужского региона. В Калужской области, согласно закону «Об образовании в Калужской области», органами государственной власти, осуществляющим государственное управление в сфере, образования являются:

- Законодательное Собрание Калужской области;

- Правительство Калужской области;

- Орган исполнительной власти Калужской области, осуществляющий государственное управление в сфере образования;

- иные органы исполнительной власти Калужской области, имеющие в своем ведении организации, осуществляющие образовательную деятельность [3].

Как показало проведенное ранее исследование, «в последние годы финансовое обеспечение социальной сферы не утратило своей значимости, ей по-прежнему уделяется огромное внимание. Это находит свое подтверждение в постоянно растущем объеме расходов на различные направления, а также в успешной реализации региональных целевых программ, направленных на развитие образования, здравоохранения, культуры и поддержание физической культуры и массового спорта в Калужском регионе» [7, 69].

Возвращаясь к уровням образования, отметим, что дошкольное образование в Калужской области представлено преимущественно детскими садами. В них дети обучаются азам устного счета и русского алфавита до 6 лет. Кроме того, во многих дошкольных учреждениях на сегодняшний день преподают основы английского языка. Количество дошкольных учреждений и обучающихся в них детей в Калужской области в 2010-2014 годах можно проследить по таблице 1.

Таблица 1

Динамика количества дошкольных учреждений и численности детей в данных учреждениях в Калужской области 2010-2014 гг.

\begin{tabular}{|c|c|c|c|c|c|c|c|}
\hline \multirow{2}{*}{ Исследуемый показатель } & \multicolumn{5}{|c|}{ Годы } & \multicolumn{2}{|c|}{ Изменение 2014 к 2010 г. } \\
\hline & 2010 & 2011 & 2012 & 2013 & 2014 & BHB & $\%$ \\
\hline $\begin{array}{c}\text { Количество дошкольных } \\
\text { учреждений, ед. }\end{array}$ & 264 & 267 & 273 & 271 & 250 & -14 & $-5,30$ \\
\hline Темп прироста, \% & $\mathrm{x}$ & $+1,14$ & $+2,25$ & $-0,73$ & $-7,75$ & $\mathrm{x}$ & $\mathrm{x}$ \\
\hline $\begin{array}{c}\text { Численность детей в } \\
\text { дошкольных учреждениях, тыс. } \\
\text { чел. }\end{array}$ & 35,7 & 37,1 & 39,3 & 42,1 & 45,2 & $+9,5$ & $+26,61$ \\
\hline Темп прироста, \% & $\mathrm{x}$ & $+3,92$ & $+5,93$ & $+7,12$ & $+7,36$ & $\mathrm{x}$ & $\mathrm{x}$ \\
\hline
\end{tabular}

Источник: рассчитано и составлено автором на основании данных [12].

Условные обозначения: ВНВ - в натуральном выражении.

Анализируя вышеуказанные данные, следует заметить, что количество дошкольных учреждений в Калужской области за последние 5 лет сократилась на 5,3\% (что в натуральном выражении составляет 14 единиц). При этом, если до 2012 года включительно наблюдается положительный прирост дошкольных учреждений, то в период 2012 - 2014 гг. прирост становится отрицательным. В то же время, численность детей, обучающихся в дошкольных учреждениях, имеет четкую тенденцию к увеличению. Об этом свидетельствуют исключительно положительные приросты в исследуемом периоде. В целом за 2010-2014 гг. численность детей увеличилась на $26,61 \%$ (что в натуральном выражении составляет 9,5 тыс. чел.). Данный парадокс связан, прежде всего, с неравномерностью распределения населения. В деревнях наблюдается нехватка детей для

ISPC Intelligent technologies,

Marseille, France обеспечения нормального функционирования детских садов, в то время как в городах прослеживается высокий абсолютный прирост населения, где детские сады переполнены, а родители встают в очередь на годы вперед.

После окончания детского сада по достижении 7 лет дети поступают в начальную школу. Продолжительность обучения начальному образованию - 4 года. В Калужской области начальная школа преимущественно не отделена от среднего или основного общеобразовательного учреждения, то есть в одной школе, гимназии или лицее ребенок имеет возможность получить образование с 1 по 11 или с 1 по 9 класс соответственно.

В начальной школе детям преподаются основы русского языка, математики, окружающего мира, чтения. Также широко распространен в начальных классах такой 
предмет как основы православной культуры, прививающий с раннего возраста детям христианские обычаи и догматы.

Стоит заметить, что на сегодняшний день начальные школы массово внедряют федеральные государственные общеобразовательные стандарты начального образования, по которым предусмотрено увеличение количества часов на внеурочную деятельность. Внеурочная деятельность - это образовательная деятельность, отличающаяся по своей форме от классово-урочных занятий, и направленная на достижение усвоения программы начального общего образования [9, с. 183]. Таким образом, можно сказать, что детей уже с начальной школы приучают к самообразованию.

По окончании 4 класса ученики пишут «срезовые» контрольные работы по основным предметам - русскому языку и математике, и по результатам переходят на следующий уровень образования.

Основное общее образование дети получают на протяжении 5 лет, с 5 по 9 класс. На данном этапе учащимся даются знания по главным направлениям наук. Количество изучаемых дисциплин в основной школе доходит до 20. По окончании 9 класса учащиеся сдают основные государственные экзамены (ГИА) в обязательном порядке. На сегодняшний день существует 2 формы государственной итоговой аттестации:

- ОГЭ (основной государственный экзамен) - форма государственной итоговой аттестации по образовательным программам основного общего образования;

- ГВЭ (государственный выпускной экзамен) - форма ГИА в виде письменных и устных экзаменов с использованием текстов, тем, заданий, билетов [14].

Важно подчеркнуть, что в рамках данной статьи будет рассматриваться такая форма, как ОГЭ. Каждый ученик сдает ОГЭ по русскому языку и математике и еще двум предметам по выбору (с 2014 года выбор дисциплин необязателен, достаточно обязательных предметов). Данная процедура необходима для перехода в старшую школу или для поступления в учреждение среднего профессионального образования. К сдаче данного экзамена допускаются:

- выпускники

9 классов общеобразовательных учреждений Российской Федерации с годовыми отметками по всем предметам не ниже «3»;

- выпускники с одной «2», с условием, что будут сдавать экзамен по этому предмету;

- иностранные граждане, лица без гражданства, беженцы и вынужденные

ISPC Intelligent technologies,

Marseille, France переселенцы, обучающиеся

B общеобразовательном учреждении;

- выпускники прошлых лет, не получившие аттестат [17].

ОГЭ проводится с использованием контрольных измерительных материалов, представляющих собой комплексы заданий стандартизированной формы (КИМ), а также с использованием специальных бланков для записи ответов на задания. Ранее комплекс заданий состоял из трех частей: «А» - тестовой части, «В» - части с кратким ответом и «С» - части с развернутым ответом, но с 2015 года КИМ содержит всего две части без буквенных обозначений $\mathrm{A}, \mathrm{B}, \mathrm{C}$ в режиме сквозной нумерации: тестовую часть и часть, подразумевающую решение или развернутый ответ. При этом в тестовой части также изменилась форма записи ответов. Теперь вместо выбора варианта требуется записать цифры, соответствующие номерам правильных ответов [14]. После сдачи экзаменов учащиеся получают аттестат об основном общем образовании.

Среднее общее образование предполагает подготовку учащихся в высшее образовательное учреждение, включает в себя 10-11 классы. Помимо дисциплин, изучавшихся в основной школе, добавляется небольшое количество новых, список которых в разных школах очень варьируется (наиболее распространенный для появления в 10-11 классах предмет - это астрономия). Экзамены в старшей школе представляют собой единые государственные экзамены (ЕГЭ), которые могут проводиться по 9 дисциплинам, изучаемым в школе. Данный экзамен позволяет сравнивать всех учащихся, находящихся на территории Российской Федерации, по уровню подготовки, ведь он проводится на русском языке (за исключением ЕГЭ по иностранным языкам), содержит однотипные задания и единую шкалу оценки. ЕГЭ представлен в той же форме, что и ОГЭ - в виде комплекса заданий (КИМ) и специальных бланков для ответов. Обязательными предметами для сдачи в виде ЕГЭ являются русский язык и математика. Остальные предметы являются предметами по выбору, которые учащиеся сдают, исходя из своих способностей, приоритетов и той специальности, которой они хотят обучаться.

Стоит отметить, что ранее ЕГЭ состоял из трех частей: «А» - тестовая часть, «В»- часть с краткими свободными ответами, «С» - часть с развернутыми свободными ответами. Однако, с 2015 года КИМ содержит всего две части: с краткими ответами и с развернутыми ответами, без буквенных обозначений А, В, С и со сквозной нумерацией. Результаты ЕГЭ необходимы для получения школьного аттестата о полном среднем образовании, а также они учитываются 


\section{Impact Factor:}

\begin{tabular}{|c|c|c|}
\hline ia) & $=1.3$ & SIS (USA) \\
\hline & & РИНЦ (Russia) \\
\hline 1a) & $=0$. & ESJI (KZ) \\
\hline IF & $=1.5$ & SJIF $($ Morocco $)=\mathbf{2}$ \\
\hline
\end{tabular}

при поступлении в высшие учебные заведения [13].

Динамику численности как государственных и муниципальных, так и негосударственных общеобразовательных учреждений в Калужской области в 2010-2014 г. можно проследить в таблице 2.

Общеобразовательные учреждения в Калужской области в 2010-2014 гг.

Таблица 2

\begin{tabular}{|c|c|c|c|c|c|c|c|}
\hline \multirow[t]{2}{*}{ Исследуемый показатель } & \multicolumn{5}{|c|}{ Годы } & \multicolumn{2}{|c|}{$\begin{array}{l}\text { Изменение } \\
2014 \text { к } 2010 \\
\text { году }\end{array}$} \\
\hline & 2010 & 2011 & 2012 & 2013 & 2014 & BHB & $\%$ \\
\hline $\begin{array}{c}\text { Дневные государственные и муниципальные } \\
\text { общеобразовательные учреждения, ед. }\end{array}$ & 390 & 374 & 369 & 362 & 347 & -43 & $-11,03$ \\
\hline Темп прироста, \% & $\mathrm{x}$ & $-4,10$ & $-1,34$ & $-1,90$ & $-4,14$ & $\mathrm{x}$ & $\mathrm{x}$ \\
\hline $\begin{array}{c}\text { Дневные } \\
\text { негосударственныеобщеобразовательные } \\
\text { учреждения, ед. }\end{array}$ & 11 & 13 & 13 & 11 & 13 & +2 & $+18,18$ \\
\hline Темп прироста, \% & $\mathrm{x}$ & $+18,18$ & 0 & $-15,38$ & $+18,18$ & $\mathrm{x}$ & $\mathrm{x}$ \\
\hline $\begin{array}{c}\text { Вечерние (сменные) общеобразовательные } \\
\text { учреждения, ед. }\end{array}$ & 6 & 6 & 4 & 3 & 2 & -4 & $-66,67$ \\
\hline Темп прироста, \% & $\mathrm{x}$ & 0 & $-33,33$ & -25 & $-33,33$ & $\mathrm{x}$ & $x$ \\
\hline Общеобразовательные учреждения всего, ед. & 407 & 393 & 386 & 376 & 362 & -45 & $-11,06$ \\
\hline Темп прироста, \% & $\mathrm{x}$ & $-3,44$ & $-1,78$ & $-2,59$ & $-3,72$ & $\mathrm{x}$ & $\mathrm{x}$ \\
\hline
\end{tabular}

Источник: рассчитано и составлено автором на основании данных [12].

На основе данных таблицы 2 можно сделать выводы, что в 2010-2014 гг. общее число общеобразовательных учреждений сократилось на 45 единиц (что в процентном выражении составляет 11,06 \%), из которых 43 единицы являются дневными государственными и муниципальными общеобразовательными учреждениями. Стоит также заметить, что какойлибо закономерности в увеличении дневных негосударственных общеобразовательных учреждений не наблюдается, так как темп прироста не имеет постоянного знака.

Вместе с уменьшением количества общеобразовательных учреждений в Калужской области в 2012-2014 гг. наблюдается увеличение численности учащихся в данных организациях (табл.3).

Таблица 3

Численность учащихся в общеобразовательных учреждениях в Калужской области в 2010-2014 гг.

\begin{tabular}{|c|c|c|c|c|c|c|c|}
\hline \multirow[t]{2}{*}{ Исследуемый показатель } & \multicolumn{5}{|c|}{ Годы } & \multicolumn{2}{|c|}{$\begin{array}{c}\text { Изменение } 2014 \text { к } \\
2010 \text { году }\end{array}$} \\
\hline & 2010 & 2011 & 2012 & 2013 & 2014 & $\mathrm{BHB}$ & $\%$ \\
\hline $\begin{array}{c}\text { Численность учащихся в дневных } \\
\text { государственных и муниципальных } \\
\text { учреждениях, тыс. чел. }\end{array}$ & 85,6 & 86,8 & 87,3 & 89,0 & 92,3 & $+6,7$ & $+7,83$ \\
\hline Темп прироста, \% & $\mathrm{x}$ & $+1,40$ & $+0,58$ & $+1,95$ & $+3,71$ & $\mathrm{x}$ & $\mathrm{x}$ \\
\hline $\begin{array}{c}\text { Численность учащихся в дневных } \\
\text { негосударственных учреждениях, тыс.чел. }\end{array}$ & 0,9 & 1,4 & 1,5 & 1,4 & 1,4 & $+0,5$ & $+55,56$ \\
\hline Темп прироста, \% & $\mathrm{x}$ & $+55,56$ & $+7,14$ & $-6,67$ & 0 & $\mathrm{x}$ & $\mathrm{x}$ \\
\hline $\begin{array}{c}\text { Численность учащихся в вечерних } \\
\text { общеобразовательных учреждениях, тыс. } \\
\text { чел. } \\
\end{array}$ & 1,3 & 1,4 & 1,2 & 1,0 & 1,8 & $+0,5$ & $+38,46$ \\
\hline Темп прироста, \% & $\mathrm{x}$ & $+7,69$ & $-14,29$ & $-16,67$ & $+80,00$ & $\mathrm{x}$ & $\mathrm{x}$ \\
\hline $\begin{array}{c}\text { Численность учащихся в } \\
\text { общеобразовательных учреждениях всего, } \\
\text { тыс. чел. } \\
\end{array}$ & 87,8 & 89,6 & 90,0 & 91,4 & 95,5 & $+7,7$ & $+8,77$ \\
\hline Темп прироста, \% & $\mathrm{X}$ & $+2,05$ & $+0,45$ & $+1,56$ & $+4,49$ & $\mathrm{x}$ & $\mathrm{x}$ \\
\hline
\end{tabular}

Источник: рассчитано и составлено автором на основании данных [12].

ISPC Intelligent technologies,

Marseille, France 
Анализ таблицы 3 позволяет подтвердить наличие тенденции увеличения численности учащихся в общеобразовательных учреждениях Калужской области в 2010-2014 гг. Так, общая численность учащихся возросла на $8,77 \%$ (что в натуральном выражении составляет 7,7 тыс. человек). При этом однозначное увеличение учащихся наблюдается в дневных государственных и муниципальных учреждениях - на 7,83 \% (что в натуральном выражении составляет 6,7 тыс. человек). Численность учащихся в исследуемый период времени в дневных негосударственных и вечерних общеобразовательных учреждениях очень динамична и не позволяет выявить каких-либо закономерностей.
Таким образом, в области среднего образования региона в исследуемом периоде наблюдается увеличение численности учащихся при одновременном уменьшении числа общеобразовательных учреждений.

Как и в случае с дошкольными организациями, данная динамика обусловлена упразднением многих деревенских и сельских государственных (преимущественно государственными являются школы-интернаты для детей сирот, а также для обучающихся с отклонениями в развитии) и муниципальных школ. Тем не менее, расходы бюджета на образование в 2010-2014 годах имеют тенденцию к увеличению (табл. 4).

Расходы областного бюджета Калужской области на образование в 2010-2014 гг., млн. руб.

\begin{tabular}{|c|c|c|c|c|c|}
\hline Год & 2010 & 2011 & 2012 & 2013 & 2014 \\
\hline Дошкольное образование & 13,24 & 77,10 & 63,45 & 399,39 & 3159,41 \\
\hline Общее образование & 998,66 & 4778,10 & 6378,80 & 6225,24 & 6018,71 \\
\hline $\begin{array}{c}\text { Начальное профессиональное } \\
\text { образование }\end{array}$ & 242,95 & 148,48 & 157,65 & 95,86 & - \\
\hline $\begin{array}{c}\text { Среднее профессиональное } \\
\text { образование }\end{array}$ & 649,48 & 795,51 & 1250,17 & 1242,66 & 1194,29 \\
\hline $\begin{array}{c}\text { Профессиональная подготовка, } \\
\text { переподготовка и повышение } \\
\text { квалификации }\end{array}$ & 54,39 & 139,84 & 124,91 & 150,01 & 122,66 \\
\hline $\begin{array}{c}\text { Молодежная политика и } \\
\text { оздоровление детей }\end{array}$ & 168,61 & 207,66 & 231,56 & 236,50 & 286,03 \\
\hline $\begin{array}{c}\text { Другие вопросы в области } \\
\text { образования }\end{array}$ & 254,47 & 295,66 & 243,12 & 257,18 & 287,46 \\
\hline Всего & 2381,80 & 6442,35 & 8449,66 & 8606,84 & 11068,56 \\
\hline
\end{tabular}

Источник: составлено автором на основании данных [4], [15].

Анализируя данные таблицы 4, необходимо отметить, что в исследуемом периоде расходы областного бюджета Калужской области на образование постоянно увеличиваются. Так, за 5 лет они возросли на 8,69 млрд. руб. При этом, ежегодное увеличение расходов наблюдается в области молодежной политики и оздоровления детей. В 2014 году резко возросли расходы на дошкольное образование - на 2,76 млрд. руб. по сравнению с 2013 годом. Расходы по другим вопросам в области образования сократились в 2012 году на 52,54 млн. руб. по сравнению с 2011 годом, но уже в 2014 году увеличились на 44,34 млн. руб. по сравнению с 2012 годом. Расходы по остальным подразделам образования уменьшаются с 2012 года, за исключением расходов на профессиональную подготовку, переподготовку и повышение квалификации, которые в 2013 году возросли на 25,1 млн. руб. по сравнению с 2012 годом, но уже в 2014 году сократились на 27,35 млн. руб. по сравнению с

\section{3 годом.}

Что касается начального профессионального образования, то с 2014 года средства областного бюджета Калужской области на данный вид образования выделяться не будут, в связи с тем, что согласно Федеральному закону от 29.12.2012 №273-Ф3 «Об образовании в Российской Федерации» с 1.09.2013 упразднены такие понятия, как программы начального профессионального образования и учреждения начального профессионального образования [15].

Вследствие этого, получив основное общее образование, подросток в настоящее время имеет право по результатам ОГЭ поступить только в учреждение среднего профессионального образования. Данными учреждениями являются техникумы и колледжи, в которых период обучения составляет 2-4 года в зависимости от выбранной учащимся специальности [16]. По предметам, по которым не проводится основной государственный экзамен, учреждения среднего 
профессионального образования вправе проводить самостоятельные вступительные испытания. В данные учреждения выпускник вправе поступить и по окончании старшей школы по результатам ЕГЭ.
Динамика количества учреждений среднего профессионального образования и численность обучающихся студентов в Калужской области в 2010-2014 гг. представлена в таблице 5.

Таблица 5

Учреждения среднего профессионального образования и обучающихся студентов в Калужской области в 2010-2014 гг.

\begin{tabular}{|c|c|c|c|c|c|c|c|}
\hline \multirow{2}{*}{ Исследуемый показатель } & \multicolumn{9}{|c|}{ Годы } & \multicolumn{2}{c|}{$\begin{array}{c}\text { Изменене } 2014 \text { к } 2010 \\
\text { году }\end{array}$} \\
\cline { 2 - 8 } & 2010 & 2011 & 2012 & 2013 & 2014 & ВНВ & $\%$ \\
\hline Количество учреждений, ед. & 28 & 28 & 30 & 28 & 28 & 0 & 0 \\
\hline Темп прироста, \% & $\mathrm{x}$ & 0 & $+7,14$ & $-6,67$ & 0 & $\mathrm{x}$ & $\mathrm{x}$ \\
\hline $\begin{array}{c}\text { Численность студентов, тыс. } \\
\text { чел. }\end{array}$ & 13,3 & 13,2 & 13,0 & 12,8 & 12,7 & $-0,6$ & $-4,51$ \\
\hline Темп прироста, \% & $\mathrm{x}$ & $-0,75$ & $-1,52$ & $-1,54$ & $-0,78$ & $\mathrm{x}$ & $\mathrm{x}$ \\
\hline
\end{tabular}

Источник: рассчитано и составлено автором на основании данньх [12].

Анализ таблицы 5 позволяет сделать вывод о том, что в условиях проводимой реформы государственных (муниципальных) учреждений в Калужской области количество учреждений среднего профессионального образования за 2010-2014 гг. в целом не изменилось. Если в 2012 году их количество и увеличилось на 2 единицы, то уже в 2013 году - сократилось вновь на 2 единицы. Численность студентов в этот период уменьшилась на $4,51 \%$ (что в натуральном выражении составляет 0,6тыс. человек). При этом тенденция уменьшения численности учащихся прослеживается во всем исследуемом периоде. Одной из причин уменьшения числа студентов является сокращение в колледжах и техникумах бюджетных мест, что, в свою очередь, делает невозможным обучение детей, в чьих семьях низкий уровень доходов.

После окончания учреждения среднего профессионального образования, студенты вправе поступить в высшее учебное заведение как по своей специальности (сразу на 2 или 3 курс бакалавриата, в зависимости от вуза), так и по другой (на 1 курс бакалавриата). Для поступления в вуз выпускнику колледжа или техникума необходимо будет предъявить диплом об окончании учреждения среднего профессионального образования, а также сдать ЕГЭ по необходимым предметам.

Повышение уровня и качества высшего профессионального образования необходимо не только для государства в целом, но и для каждого региона Российской Федерации в частности, ведь высшее образование способствует формированию человеческого капитала, созданию баз знаний, распространению и использованию данных знаний, а также их обслуживанию [10, с. 29].

Высшие учебные заведения в Калужской области в основном представлены университетами, но также присутствуют академии и институты, динамика количества которых варьируется каждый год, преимушественно вследствие закрытия филиалов, так широко распространенных на территории данного региона. Более подробно показатели динамики количества высших учебных заведений в Калужской области в 20122014 гг. указаны в таблице 6.

Таблица 6

\section{Динамика количества высших учебных заведений и численности обучающихся студентов в Калужской области в 2010-2014 гг.}

\begin{tabular}{|c|c|c|c|c|c|c|c|}
\hline \multirow{2}{*}{\begin{tabular}{c} 
Исследуемый показатель \\
\cline { 2 - 8 }
\end{tabular}} & \multicolumn{9}{|c|}{ Годы } & $\begin{array}{c}\text { Изменение 2014 } \\
\text { к 2010 году }\end{array}$ \\
\cline { 2 - 8 } & 2010 & 2011 & 2012 & 2013 & 2014 & ВНВ & \% \\
\hline $\begin{array}{c}\text { Количество государственных } \\
\text { учреждений, ед. }\end{array}$ & 16 & 16 & 15 & 14 & 14 & -2 & $-12,5$ \\
\hline $\begin{array}{c}\text { Темп прироста, \% } \\
\text { Численность студентов в } \\
\text { государственных вузах, тыс. чел. }\end{array}$ & 25,0 & 23,0 & 21,7 & 21,2 & 19,3 & $-5,7$ & $-22,8$ \\
\hline
\end{tabular}

ISPC Intelligent technologies, 


\section{Impact Factor:}

\begin{tabular}{lr|lr} 
ISRA $($ India) & $=\mathbf{1 . 3 4 4}$ & SIS $($ USA) & $=\mathbf{0 . 9 1 2}$ \\
ISI $($ Dubai, UAE) & $=\mathbf{0 . 8 2 9}$ & PИНЩ (Russia) $=\mathbf{0 . 1 7 9}$ \\
GIF $($ Australia) & $=\mathbf{0 . 3 5 6}$ & ESJI $($ KZ) & $=\mathbf{1 . 0 4 2}$ \\
JIF & $=\mathbf{1 . 5 0 0}$ & SJIF $($ Morocco $)$ & $=\mathbf{2 . 0 3 1}$
\end{tabular}

\begin{tabular}{|c|c|c|c|c|c|c|c|}
\hline Темп прироста, \% & $\mathrm{x}$ & -8 & $-5,65$ & $-2,30$ & $-8,96$ & $\mathrm{x}$ & $\mathrm{x}$ \\
\hline $\begin{array}{c}\text { Количество негосударственных } \\
\text { учреждений, ед. }\end{array}$ & 12 & 12 & 11 & 8 & 7 & -5 & $-41,67$ \\
\hline Темп прироста, \% & $\mathrm{x}$ & 0 & $-8,33$ & $-27,27$ & $-12,5$ & $\mathrm{x}$ & $\mathrm{x}$ \\
\hline $\begin{array}{c}\text { Численность студентов в } \\
\text { негосударственных вузах, тыс. чел. }\end{array}$ & 12,6 & 10,8 & 8,5 & 6,6 & 5,5 & $-7,1$ & $-56,35$ \\
\hline Темп прироста, \% & $\mathrm{x}$ & $-14,29$ & $-21,30$ & $-22,35$ & $-16,67$ & $\mathrm{x}$ & $\mathrm{x}$ \\
\hline Количество вузов всего, ед. & 28 & 28 & 26 & 22 & 21 & -7 & -25 \\
\hline Темп прироста, \% & $\mathrm{x}$ & 0 & $-7,14$ & $-15,38$ & $-4,55$ & $\mathrm{x}$ & $\mathrm{x}$ \\
\hline Численность студентов всего, чел. & 37,6 & 33,8 & 30,2 & 27,8 & 24,8 & $-12,8$ & $-34,04$ \\
\hline Темп прироста, \% & $\mathrm{x}$ & $-10,11$ & $-10,65$ & $-7,95$ & $-10,79$ & $\mathrm{x}$ & $\mathrm{x}$ \\
\hline
\end{tabular}

Источник: рассчитано и составлено автором на основании данньх [12].

Анализ таблицы 6 позволяет выявить сокращение в 2010-2014 гг. численности студентов в высших учебных заведениях на $12,8 \%$ (что в натуральном выражении составляет 34,04 тыс. чел.). Количество учреждений высшего профессионального образования также сокращается. За данный период времени было упразднено $25 \%$ вузов (что в натуральном выражении составляет 7 единиц).

В высших учебных заведениях Калужской области можно получить как степень бакалавра, так и степень магистранта. Необходимо отметить, что с 2011 года набор в высшие учебные заведения на освоение программ специалитета по большинству направлений не производится.

Исходя из всего вышеизложенного, можно сделать вывод о том, что в 2010-2014 гг. в Калужской области наблюдается тенденция роста числа детей дошкольного и школьного возраста в дошкольных и общеобразовательных учреждениях при одновременном сокращении числа данных организаций. Вместе с тем, расходы областного бюджета в данном регионе на образование в этот период времени возрастают. Причина сложившейся ситуации кроется в упразднении сельских детских садов и школ вследствие отсутствия достаточного количества учащихся и развитии городских дошкольных и общеобразовательных учреждений. В области среднего и высшего профессионального образования в 2010-2014 гг. можно проследить отток студентов из региона с одновременным сокращением числа учреждений среднего и высшего профессионального образования, однако это общая тенденция в стране.

Научное исследование выполнено под руководством Н.С.Сергиенко, к.э.н., доцента кафедры «Финансы и кредит» Калужского филиала Финансового университета при Правительстве Российской Федерации.

\section{References:}

1. (2014) Konstitucija Rossijskoj Federacii (s uchetom popravok, vnesennyh Zakonami RF o popravkah k Konstitucii RF ot 30.12.2008 N 6FKZ, ot 30.12.2008 N 7-FKZ, ot 05.02.2014 N 2-FKZ, ot 21.07.2014 N 11-FKZ).

2. (2015) Federal'nyj zakon ot 29.12.2012 №273FZ «Ob obrazovanii v Rossijskoj Federacii» (red. ot 31.12.14, s izm. ot 06.04.2015).

3. (2013) Zakon Kaluzhskoj oblasti ot 30 sentjabrja 2013 g. N 479-OZ «Ob obrazovanii v Kaluzhskoj oblasti».

4. (2015) Zakon Kaluzhskoj oblasti ot 26.06.2015 №742 - $\mathrm{OZ}$ «Ob ispolnenii oblastnogo bjudzheta za 2014 god».

5. Sergienko NS (2011) Organizacija ispolnenija bjudzheta: uchebnoe posobie. Kaluga: izd-vo OOO «Vashdom». 2011. 232 p.
6. Balynin IV (2014) Finansovoe obespechenie obrazovanija v Rossijskoj Federacii v 20082020 gg. Audit I finansovyj analiz. 2014. № 6. pp. 271-276.

7. Balynin IV (2014) Finansovoe obespechenie social'noj sfery v Kaluzhskoj oblasti v 20082016 godah. Cennosti I interesy sovremennogo obshhestva Jekonomika i upravlenie. 2014. pp. 66-69.

8. Balynin IV (2013) Obrazovanie kak prioritetnoe napravlenie rashodov bjudzhetov bjudzhetnoj sistemy Rossijskoj Federacii. Chelovek v XXI veke Materialy VIII Mezhdunarodnoj nauchno-prakticheskoj konferencii prepodavatelej i studentov. 2013. pp. 75-76.

9. Ivanova IV (2015) Razrabotka modeli soprovozhdenija samorazvitija uchashhihsja vo 


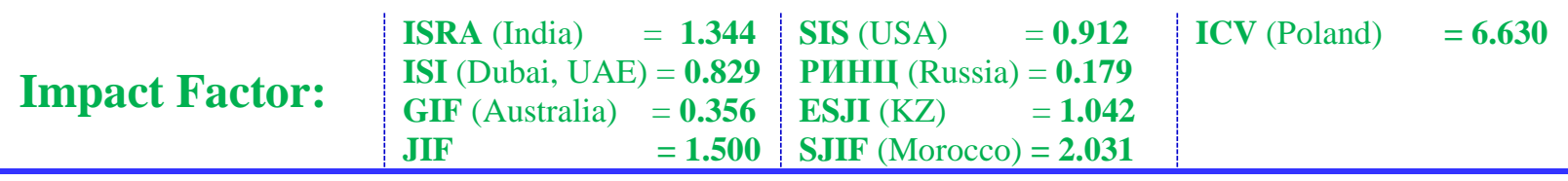

vneurochnoj dejatel'nosti v uslovijah osvoenija FGOS nachal'nogo obshhego obrazovanija na primere sel'skih shkol Kaluzhskojoblasti. VestnikTomskogo gosudarstvennogo universiteta. 2015. № 391. pp. 183-194.

10. Sysoeva SV (2013) Vysshee professional'noe obrazovanie v jekonomike znanij. Upravlencheskij uchet. 2013. № 9. pp. 23-31.

11. Sergienko NS (2013) Jekonomicheskoe obrazovanie: podhody k ocenke jeffektivnosti. Chelovek v XXI veke: materialy VIII Mezhdunarodnoj nauchno-prakticheskoj konferencii prepodavatelej i studentov, 2013, pp.137-138.

12. (2015) Federal'naja sluzhba gosudarstvennoj statistiki. Available: http://gks.ru (Accessed: 18.07.2015).

13. (2015) Federal'nyj portal Rossijskogo obrazovanija. http://www.edu.ru/abitur/act.8/index.php (Accessed: 18.07.2015).

14. (2015) Oficial'nyj informacionnyj portal gosudarstvennoj itogovoj attestacii. Available: http://gia.edu.ru/ru/main/ (Accessed: 18.07.2015).

15. (2015) Oficial'nyj portal organov vlasti Kaluzhskoj oblasti. Available: http://www.admoblkaluga.ru/ (Accessed: 18.07.2015).

16. (2015) Garant - informacionno-pravovoj portal. Available: http://base.garant.ru/193595/ (Accessed: 18.07.2015).

17. (2015) Moskovskij finansovo-juridicheskij universitet.

Available: http://www.moeobrazovanie.ru/cto takoe oge. html (Accessed: 18.07.2015). 


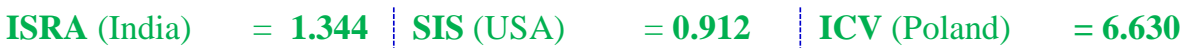

Impact Factor:

ISI $($ Dubai, UAE $)=0.829 \quad$ РИНЦ $($ Russia $)=0.179$

GIF (Australia) $=\mathbf{0 . 3 5 6} \quad$ ESJI $(\mathrm{KZ}) \quad=\mathbf{1 . 0 4 2}$

\begin{tabular}{ll|l|}
$\mathrm{JIF}$ & $\mathbf{1} 1.500$ & $\mathrm{SJIF}($ Morocco $)=\mathbf{2 . 0 3 1}$ \\
\hline
\end{tabular} 